\title{
Les Algériens au café. Textes rassemblés par Leïla Sebbar
}

\section{Paola Martini}

\section{(2) OpenEdition}

10 Journals

\section{Édition électronique}

URL : http://journals.openedition.org/studifrancesi/30872

DOI : 10.4000/studifrancesi.30872

ISSN : 2421-5856

Éditeur

Rosenberg \& Sellier

\section{Édition imprimée}

Date de publication : 1 avril 2006

Pagination : 199-200

ISSN : 0039-2944

\section{Référence électronique}

Paola Martini, «Les Algériens au café. Textes rassemblés par Leïla Sebbar », Studi Francesi [En ligne], 148 (XLX | I) | 2006, mis en ligne le 30 novembre 2015, consulté le 22 avril 2021. URL : http:// journals.openedition.org/studifrancesi/30872 ; DOI : https://doi.org/10.4000/studifrancesi.30872

Ce document a été généré automatiquement le 22 avril 2021.

\section{(c) (i) (9)}

Studi Francesi è distribuita con Licenza Creative Commons Attribuzione - Non commerciale - Non opere derivate 4.0 Internazionale. 


\title{
Les Algériens au café. Textes rassemblés par Leilla Sebbar
}

\author{
Paola Martini
}

\section{RÉFÉRENCE}

Les Algériens au café. Textes rassemblés par Leïla SEBBAR, Neuilly, Al Manar, 2003, pp. 93.

1 Les Algériens au café, pubblicato nel 2003 dalla casa editrice Al Manar specializzata prevalentemente in letteratura del Nord Africa, è un libro incantevole da leggere e da vedere. Le preziose pagine color avorio accolgono le novelle di otto autori algerini accompagnate da undici disegni a inchiostro realizzati da Sébastien Pignon che tracciano vibranti sagome di uomini al caffè. È infatti intorno ai caffè - ai suoi spazi e ai suoi avventori - che ruotano gli otto racconti di Azouz Begag, Jamel-Eddine Bencheikh, Albert Bensoussan, Maïssa Bey, Vincent Colonna, Mohamed Kacimi, Noureddine Saadi e delle stessa Sebbar. Il caffè, presentato ora come un luogo familiare e accogliente ora come luogo mitico e misterioso, è il ritrovo per eccellenza degli uomini, e solo loro, del Nord Africa. Ogni testo insiste sul fascino del café maure, sui suoi divieti e sulla memoria della quale si fa custode da una riva all'altra del Mediterraneo.

In Algeria, come apprendiamo dalla novella di Mohamed Kacimi, questo è il luogo dove tornano volentieri a far bella mostra di sé gli zmagras (les immigrés, p. 66), coloro che vivono Labachinou (là-bas chez nous, p. 70), in Francia, sradicati dalla loro terra e dalle loro tradizioni, con l'eterna nostalgia nel cuore e l'amaro risentimento nei confronti di quell'Algeria che non ha avuto sufficienti risorse per tutti i suoi figli. Maïssa Bey racconta di aver creduto a lungo che il café maure fosse un café mort, ovvero che il luogo d'incontro degli uomini corrispondesse al cimitero, peraltro luogo d'incontro delle donne. Il malinteso offre lo spunto per sottolineare la separazione tra uomini e donne nella cultura islamica e per evocare il ricordo di alcuni caffè dei quali rammenta l'attesa immutabile nello sguardo degli avventori, proteso verso la strada. Azouz Begag ci descrive con minuzia l'atmosfera di indolenza e di sospensione temporale dei cafés 
maures di Lione, frequentati dagli immigrati maghrebini, individui precari che abitano spazi di transito, «à cheval sur les frontières, les lignes, les tranchéesı (p. 8). La novella di Vincent Colonna è divisa in due parti, ognuna delle quali rappresenta rispettivamente una prospettiva maschile e una femminile sul caffè. Lo sguardo è quello di due adolescenti. Il ragazzo immagina quello spazio prima come teatro di riconciliazione, poi di vendetta per l'offesa subita a causa di un amico. La ragazza sogna invece di potervi entrare a diciotto anni, vestita elegantemente. Ma le immagini di quel sogno proibito s'intrecciano agli incubi di essere aggredita dai clienti uomini e dal pazzo del villaggio.

3 Tutte le novelle, di fantasia o autobiografiche, hanno delineato con estrema precisione $\mathrm{i}$ contorni degli Algerini al caffè: creature sornione, fuori dal tempo che riescono a trovare un chez eux, in Algeria o altrove, solo al caffè, tra una partita di domino e le discussioni politiche, in mezzo al fumo e al profumo di spezie. 